\title{
PTERIDÓFITAS DE UM REMANESCENTE DE FLORESTA ATLÂNTICA EM SÃO VICENTE FÉRRER, PERNAMBUCO, BRASIL: PTERIDACEAE ${ }^{1}$
}

\author{
Marcio Roberto Pietrobom ${ }^{2}$ \\ Iva Carneiro Leão Barros ${ }^{3}$
}

Recebido em 09/01/2001. Aceito em 12/05/2002.

\begin{abstract}
RESUMO - (Pteridófitas de um remanescente de Floresta Atlântica em São Vicente Férrer, Pernambuco, Brasil: Pteridaceae). Foi realizado um levantamento florístico da pteridoflora da Mata do Estado, localizada no município de São Vicente Férrer, Zona da Mata Norte do Estado de Pernambuco. O estudo foi desenvolvido nesta área, devido a sua grande extensão, ca. 600ha, e também pela existência de uma grande diversidade de pteridófitas, resultado de um gradiente de umidade onde os fatores ambientais e físicos como os níveis de altitude, as precipitações pluviométricas, bem como a distribuição dessas precipitações têm importância fundamental para a vegetação da área. Foram empregados métodos tradicionais para o levantamento florístico, no período de um ano. Para a análise e identificação taxonômica dos exemplares coletados, foram utilizadas técnicas usuais e literaturas especializadas. São apresentadas ilustrações e distribuição geográfica das espécies, bem como, descrição da espécie nova referência e comentários da família, gêneros e espécies. O trabalho contribui para um maior conhecimento florístico e ecológico da pteridoflora de Reservas de Floresta Atlântica Serrana no Nordeste do Brasil. A família Pteridaceae está representada na área estudada por 20 espécies, distribuídas em sete gêneros (Pityrogramma Link, Adiantopsis Fée, Hemionitis L. e Acrostichum L. uma espécie cada; Doryopteris J. Sm. quatro espécies; Adiantum L. nove espécies e Pteris L. três espécies e uma variedade). Foi registrada uma nova referência para o estado de Pernambuco: Adiantum humile Kunze.
\end{abstract}

Palavras-chave - Florística, pteridófitas, Pteridaceae, Floresta Atlântica

\begin{abstract}
Pteridophytes of a remainder of Atlantic Forest in São Vicente Férrer, Pernambuco, Brazil: Pteridaceae.). A floristic survey of the pteridoflora at the Mata do Estado, located in the Municipality of São Vicente Férrer, Mata Norte (Atlantic Forest) Zone in the state of Pernambuco, Brazil, was performed. The study was developed in this area, due to its great extension of ca. 600ha, and also because of a great of diversity pteridophytes, result of a humidity gradient where the environmental and physical factors such as the altitude levels and the,, precipitation, as well as the distribution of those precipitations has fundamental importance for the vegetation of the area. Traditional methods were used to carry out the floristic survey. The usual methods and specialized literature were utilized for the analysis and identification of the collected specimens. Illustrations and geographic distribution of the species are presented, and also a description of new reference species and comments on families, genera and species. The work aims to contribute to a better floristic and ecological understanding of the pteridoflora of the Atlantic Forest Reserves located in the mountainous region of the Northeastern Brazil. The family Pteridaceae is represented in the studied area with by twenty especies distributed in seven genera (Pityrogramma Link, Adiantopsis Fee, Hemionitis L. with and Acrostichum L. with one specie each; Doryopteris J. Sm. with four species; Adiantum L. with nine species and Pteris L. a tree species and one variety). Adiantum humile Kunze is a new reference for the state of Pernambuco.
\end{abstract}

Key words - Floristic, pteridophytes, Pteridaceae, Atlantic Forest

${ }^{1}$ Parte da Dissertação de Mestrado do primeiro autor.

${ }^{2}$ Aluno do Programa de Pós-Graduação em Biologia Vegetal, CCB, Universidade Federal de Pernambuco, Av. Prof. Moraes Rego s.n., CEP 50.670-901, Recife, PE, Brasil. e-mail: mucurasilva@ hotmail.com

${ }^{3}$ Departamento de Botânica, CCB, Universidade Federal de Pernambuco, Av. Prof. Moraes Rego s.n., CEP 50670-901, Recife, PE, Brasil. e-mail: ivaleao@truenet.com.br 


\section{Introdução}

As pteridófitas constituem um grupo bastante heterogêneo incluindo "fósseis vivos", que crescem e vivem em vasta gama de regiões e ambientes, apresentando uma diversidade morfológica bastante acentuada e correspondentes adaptações para os variados hábitats (Windisch, 1992). Na região dos Trópicos, as pteridófitas se concentram principalmente nas Florestas Úmidas, sendo que apenas um pequeno número de espécies é capaz de crescer em outros tipos de vegetação (Holttum, 1938; Page, 1979; Kornás, 1993).

Na região Nordeste do Brasil, de modo geral, as pteridófitas têm uma distribuição relativamente ampla: no Maranhão ocorrem em áreas remanescentes de Floresta Perenifólia Higrófila Costeira com poucas referências, (Bastos \& Cutrin, 1999), citando 15 espécies; no Piauí, de maneira semelhante, também, há poucas referências, com a citação de quatro espécies (Andrade-Lima, 1969); destacam-se as ocorrências das pteridófitas nesta região, nas diversas zonas fitogeográficas que abrangem desde a Serra do Baturité, no estado do Ceará, até a Chapada Diamantina, no estado da Bahia, além daquelas ocorrentes em áreas de caatinga (Ambrósio \& Barros, 1997).

Prosseguindo com os estudos sobre a florística e a ecologia das pteridófitas ocorrentes no Nordeste brasileiro, estão sendo desenvolvidos estudos sobre a pteridoflora de Pernambuco. Dos trabalhos já publicados, destacam-se os de Barros et al. (1988), que estudaram as espécies das várias zonas fitogeográficas; Barros et al (1989), com espécies ocorrentes na zona das Caatingas; Fonseca (1992), com a florística das pteridófitas ocorrentes na Reserva do Gurjaú, município do Cabo, com o registro de 12 espécies de Pteridaceae; Barros et al. (1996), que realizaram estudos taxonômicos de espécies de pteridófitas ocorrentes na Reserva Ecológica de Caetés - município de Paulista; Barros \& Fon- seca (1996), estudaram de dois gêneros de Lycopodiaceae ocorrentes em Brejo dos Cavalos, município de Caruaru; Ambrósio \& Barros (1997), com a florística e observações ecológicas sobre as pteridófitas da Reserva Ecológica de Jangadinha - município de Jaboatão dos Guararapes, sendo a família Pteridaceae a mais bem representada com oito espécies e Barros (1997), que efetuou um ensaio biogeográfico e análise numérica das pteridófitas ocorrentes no estado de Pernambuco.

Com respeito a família Pteridaceae é importante ressaltar os estudos florísticos para a Flora da Serra do Cipó, (MG), realizados por Prado (1992), com a subfamília Cheilanthoideae e, Prado (1997) com as tribos Adiantoideae e Taenitidoideae; Graçano et al. (1998) realizaram levantamento preliminar da pteridoflora do Parque Estadual do Rio Doce (MG), sendo Pteridaceae a família mais representativa com 17 espécies e ainda Prado (2000), que trata de uma espécie nova para a Bahia: Adiantum discolor Prado, conhecida somente das florestas úmidas da costa leste do Brasil, no estado da Bahia.

A família Pteridaceae apresenta distribuição quase cosmopolita com ca. 35 gêneros, 22 ocorrendo nas Américas (Windisch, 1992). Apresenta grande heterogeneidade morfológica, a qual constitui diversidade de grupos de gêneros, reunidos em tribos ou subfamílias, cujas relações taxonômicas não são ainda esclarecidas (Prado \& Windisch, 2000). Barros et al. (1988) comentam que no Nordeste do Brasil o grupo está bem representado em áreas de mata úmida. A representatividade da família para Pernambuco é de 59 espécies e sete variedades de Pteridaceae (Barros et al., 2001).

A Mata do Estado é uma das pouquíssimas áreas remanescentes da Floresta Atlântica na Zona da Mata Norte do estado de Pernambuco, com uma área de 600ha, onde a pteridoflora compreende 94 espécies, cinco variedades e um provável híbrido, distribuída em 16 famílias e 43 
gêneros. Pteridaceae ocorre com 20 espécies e uma variedade, distribuídas em sete gêneros. A família Pteridaceae foi escolhida por ter sido a melhor representada no levantamento florístico realizado na área enfatizando este remanescente de Floresta Atlântica no Nordeste brasileiro.

\section{Material e métodos}

Vegetação no estado de Pernambuco - O estado de Pernambuco ocupa uma área de $98.079 \mathrm{~km}^{2}$ dentro da região Nordeste do Brasil e sua vegetação encontra-se tipicamente distribuída em quatro diferentes zonas fitogeográficas - litoral, mata, caatinga e savanas (Andrade-Lima, 1960 e Ferreira et al., 1985). A zona da Mata ou Floresta Atlântica caracteriza-se por um número significativo de espécies vegetais e ocupa aproximadamente $15,7 \%$ da área total do Estado (Sales et al., 1998).

Caracterização da área estudada - A Mata do Estado faz parte do complexo da Serra do Mascarenhas e Jundiá, sobre o Maciço do Planalto da Borborema. Para Rodal et al. (1998) constitui-se em um brejo de altitude; a cobertura original da área foi caracterizada como mata úmida pelo Condepe (1990) e do tipo Floresta Perenifólia Higrófila Costeira ou Floresta Ombrófila Densa por Veloso \& Góes Filho (1982). Para os autores deste trabalho, levando em consideração a flora específica de pteridófitas coletada, constitui-se de uma Floresta Ombrófila Densa e Serrana. Abrange aproximadamente 600 ha, sendo subdividida em três Matas denominadas pela população local de: Caidor, Pimenta e do Brejinho. Está situada no município de São Vicente Férrer, Zona da Mata Norte no estado de Pernambuco, a cerca de 110 $\mathrm{km}$ da cidade do Recife, com coordenadas geográficas aproximadas de $35^{\circ} 30^{\prime} 00^{\prime \prime} \mathrm{W}$ 07³5’00”'S (Fig. 1).

A sua formação vegetacional apresenta uma elevada área basal e variação quanto ao porte, provavelmente em função do tipo e profundidade do solo, bem como de condições climáticas, propiciando a presença de cinco estratos: três arbóreos, um arbustivo e um herbáceo (Rodal, et al., 1998).

Do ponto de vista hidrológico, constitui-se em uma importante Reserva Florestal contendo cerca de 32 nascentes, destacando-se aquelas que contribuem para a formação das Bacias dos Rios Siriji e Capibaribe-Mirim (CPRH, 1994).

O clima, segundo a classificação de Köeppen, enquadra-se como do tipo As', configurando-se como quente e úmido, com períodos de seca entre setembro e fevereiro, e de chuvas entre março e agosto (CPRH, 1994), ocorrendo também a chamada "precipitação oculta", resultado da intensa condensação que ocorre à noite (Rodal et al., 1998), principalmente nos meses mais frios, quando a temperatura fica em torno de $18^{\circ} \mathrm{C}$; a temperatura media anual do ar varia entre $24^{\circ}$ e $25^{\circ} \mathrm{C}$.

A geomorfologia da área apresenta-se bastante dissecada, em forma de colinas intercaladas por vales encaixados (CPRH, 1994), com níveis altimétricos variando de 650 a 750 m. Nas encostas, encontram-se afloramentos rochosos formando extensos paredões de rochas do Embasamento Cristalino Pré-Cambriano, inscrita dentro do Complexo GnaissicoMigmático que tem como litótipos predominantes granitos (CPRH, 1994), com uma cobertura vegetal mais baixa e com características distintas ao longo das mesmas e, também grandes blocos espalhados sob a densa formação vegetal.

Coleta, herborização, identificação e catalogação do material - O levantamento florístico foi realizado segundo Ambrósio \& Barros (1997), dando prioridade aos ambientes preferenciais das pteridófitas, entre o período de março/1998 e fevereiro/1999, exceto julho de 1998, e mais três coletas adicionais nos meses de maio/junho/ setembro/1999. Os espécimens foram coletados e herborizados seguindo a metodologia padrão 
para plantas vasculares (Mori et al., 1989 e Windisch, 1992).

As identificações e dados sobre a distribuição geográfica foram realizados com base nos trabalhos de Brade (1964), Sehnem (1972), Tryon \& Tryon (1982), Proctor (1985), Mickel \& Beitel (1988), Tryon \& Stolze (1989), Lellinger (1991), Windisch (1992), Fonseca (1992), Paula (1993), Prado (1989), Moran \& Riba (1995), Ambrósio \& Barros (1997) e Prado \& Windisch (2000).

Figura 1: Localização da área estudada. 1a. América do Sul; 1b. Brasil; 1c. parte da região Nordeste; 1d. estado de Pernambuco, evidenciando o município de São Vicente Férrer; 1e. município de São Vicente Férrer, localização da área de estudo.

O sistema de classificação adotado para a seqüência de apresentação dos táxons foi o proposto por Tryon \& Tryon (1982). Para observação de padrões de venação utilizou-se a técnica de Strittmatter (1973).

Os nomes dos autores de cada um dos táxons foram abreviados e padronizados de acordo com Pichi-Sermolli (1996).

Após a identificação, o material foi depositado no Herbário Prof. Geraldo Mariz (UFP) da Universidade Federal de Pernambuco, com duplicatas enviadas para vários Herbários do Brasil como doaçãosegundo o Index Herbariorum (Holmgren et al., 1990): BHCB; HB; HBR; MBM; PEUFR; SJRP; SP e SPF.

\section{Resultados e discussão}

\section{Pteridaceae}

$\mathrm{Na}$ área estudada a família está representada pôr sete gêneros e 20 espécies:

\section{Pityrogramma Link}

O gênero é caracterizado pela face abaxial da lâmina foliar coberta por indumento farináceo branco, amarelo ou rosado e os esporângios não agrupados em soros (Moran, 1995a). Gênero com 16 espécies nativas da América, África e
Madagascar, destas, 11 são espécies americanas (Tryon \& Stolze, 1989). Representado na Mata do Estado pôr uma única espécie:

\section{Pityrogramma calomelanos (L.) Link,} Handb. Gew. 3: 20. 1833.

Fig. 2-4

A espécie é distinguida das outras da família pelas pinas equilaterais; pínulas ascendentes e pela presença de indumento farináceo branco, amarelo ou rosado na superfície abaxial da lâmina foliar.

A espécie foi coletada em solo areno-argiloso de barrancos; cresce como terrícola em solos muito encharcados, freqüentemente próxima da margem dos regatos ou do açude, exposta ao sol, com poucos indivíduos. Vive associada a várias espécies do gênero Thelypteris, Cyathea microdonta (Desv.) Domin e Blechnum serrulatum Rich., comuns a esse tipo de ambiente.

Distribuição geográfica: Sul da Flórida, México, América Central, Antilhas, Venezuela, Guianas, Equador, Colômbia, Peru, Bolívia, Paraguai e Argentina (Moran, 1995a); no Brasil, ocorre nos estados do Amazonas, Piauí, Ceará, Rio Grande do Norte, Paraíba, Pernambuco, Mato Grosso, Mato Grosso do Sul, Goiás, Minas Gerais, Rio de Janeiro, São Paulo, Paraná, Santa Catarina e Rio Grande do Sul (Sehnem, 1972 e Paula, 1993). Material examinado: BRASIL. Pernambuco: São Vicente Férrer, Complexo da Serra do Mascarenhas, Mata do Estado, ca. $35^{\circ} 30^{\prime} 00^{\prime \prime} \mathrm{W}-$ $07^{\circ} 35^{\prime} 00^{\prime}$ 'S, ca. 650-750 m alt., Mata da Pimenta, 31/III/1998, Pietrobom-Silva 4222 (UFP24175; HB-83045); idem, Mata do Caidor, 22/ II/1999, Pietrobom-Silva 4525 (UFP; HB; SP; BHCB; HBR).

\section{Adiantopsis Fée}

O gênero é caracterizado pelas lâminas radiadopinadas, raque e costa tipicamente 2-aladas no lado acroscópico e pínulas geralmente decíduas com o tempo (Proctor, 1985). Adiantopsis é um 


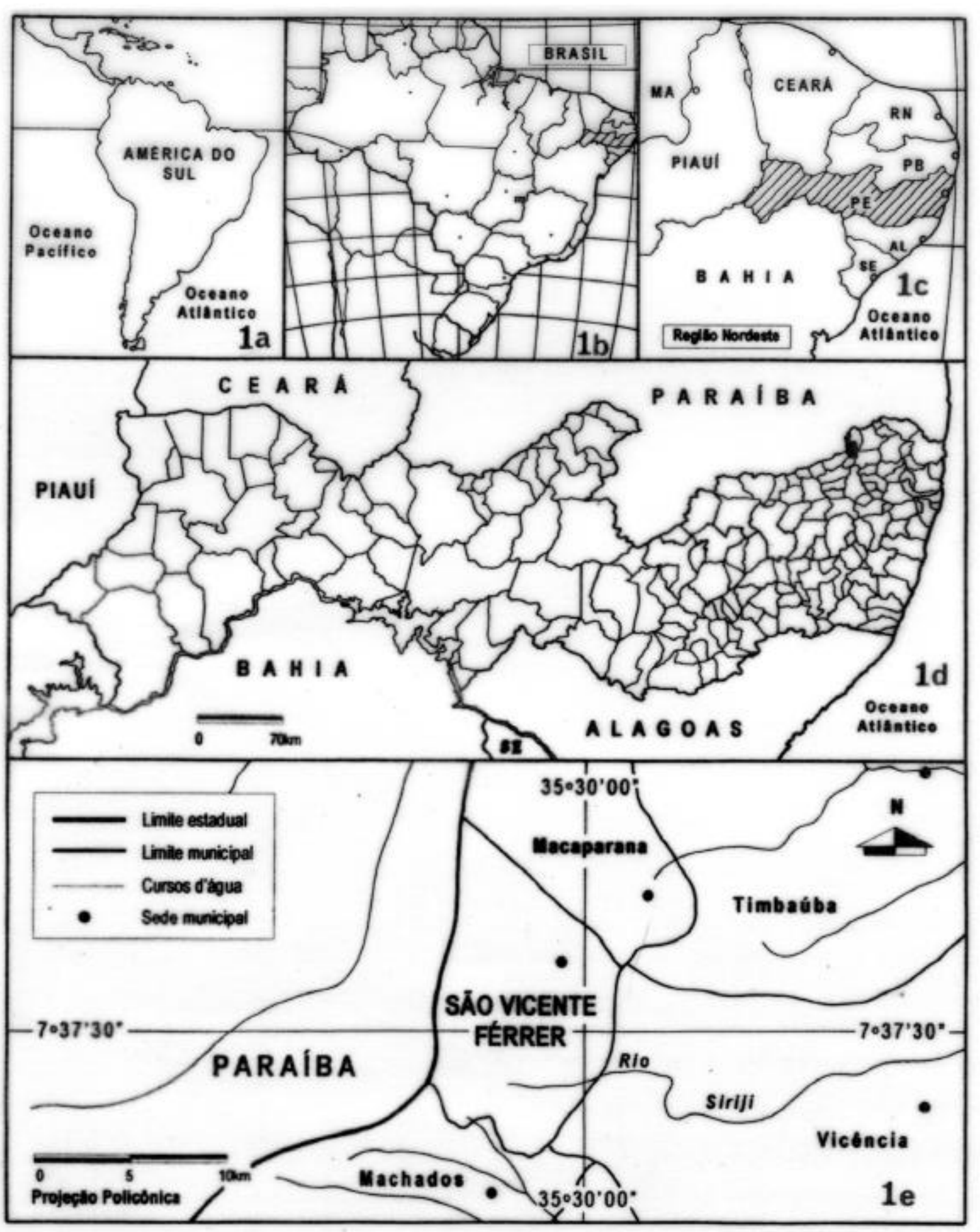

Figura 1: Localização da área estudada. 1a. América do Sul; 1b. Brasil; 1c. parte da região Nordeste; 1d. estado de Pernambuco, evidenciando o município de São Vicente Férrer; 1e. município de São Vicente Férrer, localização da área de estudo. 
gênero, que ocorre na América Tropical com ca. de sete espécies (Tryon \& Stolze, 1989). Representado na Mata do Estado por uma única espécie:

1. Adiantopsis radiata (L.) Fée, Gen. Fil. (Mém. Foug. 5) 145. 1852.

Fig. 5-6

De acordo com Tryon \& Stolze (1989) o arranjo radiado e usualmente com cinco a sete pinas, distingue Adiantopsis radiata das outras espécies da família.

$\mathrm{Na}$ área estudada foi encontrada em poucos pontos como terrícola, formando populações espalhadas pelas encostas, geralmente com poucos indivíduos dispersos ou isolados. Está geralmente associada a algumas espécies do gênero Adiantum, e também a Ctenitis distans (Brack.) Ching, Triplophyllum funestum (Kunze) Holttum, Lindsaea lancea (L.) var. falcata (Dryand.) Ros., Blechnum occidentale L. comum a esse tipo de ambiente.

Distribuição geográfica: México, América Central, Antilhas, Trinidad, Colômbia, Venezuela, Guiana, Equador, Peru, Bolívia, Paraguai e Argentina (Pacheco, 1995); no Brasil, ocorre nos estados do Ceará, Pernambuco, Alagoas, Bahia, Mato Grosso, Goiás, Espírito Santos, Rio de Janeiro, Minas Gerais, São Paulo, Paraná, Santa Catarina e Rio Grande do Sul (Sehnem, 1972 e Paula, 1993).

Material examinado: BRASIL. Pernambuco: São Vicente Férrer, Complexo da Serra do Mascarenhas, Mata do Estado, ca. 35³0'00’'W07³5'00's, ca. 650-750 m alt., Mata da Pimenta, 31/III/1998, Pietrobom-Silva 4214 (UFP; PEUFR; HB; MBM; SP; HBR); idem, 20/IV/ 1998, Pietrobom-Silva 4233 (HB); idem, Mata do Caidor, 28/VI/1998, Pietrobom-Silva 4316 (UFP; HB).

\section{Hemionitis L.}

O gênero é caracterizado pelos esporângios situados sobre as vênulas, entre a costa e a margem dos segmentos, e segmentos moderadamente pubescentes na face abaxial; gênero com sete espécies que ocorrem na América Tropical (Tryon \& Stolze, 1989). Representado na área de estudo por:

1. Hemionitis palmata L. Sp. Pl. 2: 1077. 1753. Fig. 7-8

A espécie é distinguida das outras da família pelas escamas do rizoma concolores, castanho; lâminas foliares palmadas com cinco lobos, vênulas principais escuras e geralmente com uma gema no enseio maior (Mickel \& Beitel, 1988); venação anastomosada em toda a lâmina, sem vênulas inclusas nas aréolas.

Foi coletada em apenas um ponto crescendo sobre rocha granítica humosa, local parcialmente sombreado próximo de regato, formando pequena população, com alguns indivíduos espalhados. $\mathrm{Na}$ área estudada, vive em ambientes onde aparece associada com Blechnum occidentale L., no barranco e Cyathea microdonta (Desv.) Domin, junto de regato.

Distribuição Geográfica: México, América Central, Antilhas, Colômbia, Venezuela, Guiana, Equador, Peru e Bolívia (Ranker, 1995); no Brasil, ocorre nos estados do Ceará, Pernambuco, Bahia, Goiás, Mato Grosso, Rio de Janeiro, São Paulo, Paraná, Santa Catarina e Rio Grande do Sul (Sehnem, 1972).

Material examinado: BRASIL. Pernambuco: São Vicente Férrer, Complexo da Serra do Mascarenhas, Mata do Estado, ca. 35³0'00"W07³5'00'S, ca. 650-750 m alt., Mata do Brejinho, 17/VIII/1998, Pietrobom-Silva 4406 (UFP; PEUFR; HB; MBM; SP; HBR).

Figuras 2-8. 2-4. Pityrogramma calomelanos: 2. parte da fronde; 3 . rizoma e pecíolo; 4. pínula fértil evidenciando o depósito de indumento farináceo e os esporângios (Pietrobom-Silva 4525). 5-6. Adiantopsis radiata: 5. hábito; 6. pínula mediana, face abaxial (Pietrobom-Silva 4233). Hemionitis palmata: 7. Hábito; 8. ápice do segmento central, evidenciando padrão de venação (Pietrobom-Silva 4406). 


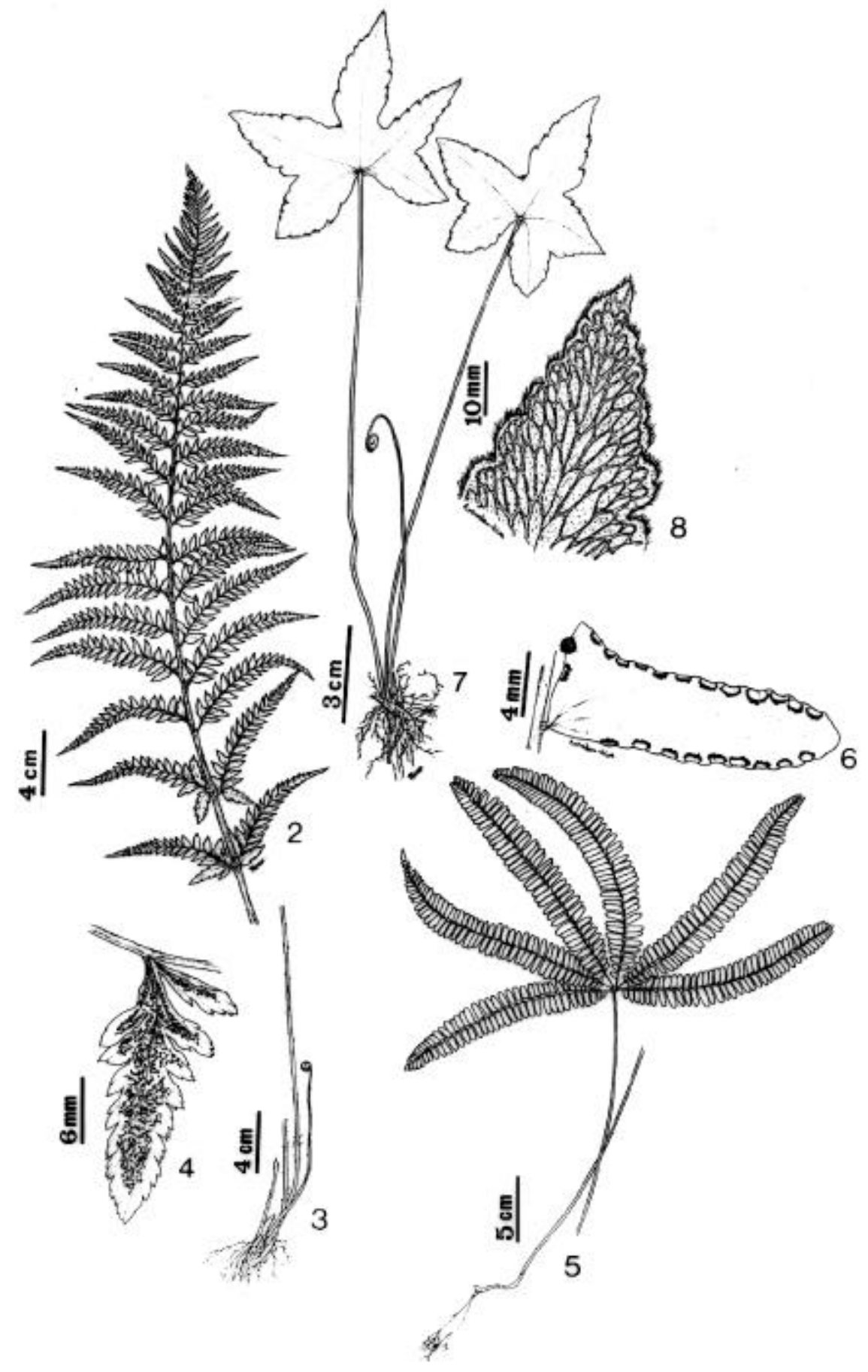

Figuras 2-8. 2-4. Pityrogramma calomelanos: 2. parte da fronde; 3. rizoma e pecíolo; 4. pínula fértil evidenciando o depósito de indumento farináceo e os esporângios (Pietrobom-Silva 4525). 5-6. Adiantopsis radiata: 5. hábito; 6. pínula mediana, face abaxial (Pietrobom-Silva 4233). Hemionitis palmata: 7. Hábito; 8. ápice do segmento central, evidenciando padrão de venação (Pietrobom-Silva 4406). 


\section{Doryopteris J. Sm.}

O gênero é caracterizado pelos pecíolos escuros esclerotizados, as lâminas pedadas, geralmente glabras, os soros submarginais contínuos e os esporângios longo-pedicelados (Moran, 1995b). Gênero pantropical com 25 espécies, divididas em duas sessões, representando linhas evolutivas distintas (Tryon \& Tryon, 1982); ocorre com maior predominância na região neotropical, principalmente na região Sudeste do Brasil (Windisch, 1983).

$\mathrm{Na}$ área estudada foram registradas quatro espécies e, em geral, crescem sobre blocos de rochas com húmus, com populações espalhadas pelas encostas no interior da mata, ou ocasionalmente entre vegetação do tipo rupestre, populações com alguns indivíduos espalhados. Santos \& Barros (1999), registraram espécies de Doryopteris em área aberta sobre intensa radiação solar, como saxícola e rupícola, ou sobre rochas com húmus. Prado (1989), registrou espécies do gênero, principalmente em afloramentos rochosos dentro das matas de galeria, às margens de rios ou córregos.

1. Doryopteris collina (Raddi) J. Sm., Job. 4: 163. 1841.

Fig. 9-11

De acordo com Brade (1964) é caracterizada pela ala da raque entre o primeiro e o segundo segmento alargada para baixo, lâmina fértil com 2-3 pares de segmentos primários, os segmentos basais parcialmente bilobados; e se diferencia das outras espécies estudadas pelo pecíolo castanho; lâminas foliares férteis bi-tripinatífidas, 5-7 segmentos primários; segmento central pinatífido e pelas costas e cóstulas pubescentes no lado abaxial da lâmina.

Foi coletada em vários pontos da área crescendo sobre blocos de rochas graníticas, com populações espalhadas pelas encostas no interior da mata formadas por poucos indivíduos não agregados. Vive em ambientes onde aparece associada a Asplenium salicifolium L.,
Asplenium serratum L. e Asplenium formosum Willd..

Distribuição geográfica: Guiana e Paraguai; no Brasil ocorre nos estados do Ceará, Pernambuco, Bahia, Minas Gerais, Rio de Janeiro, São Paulo, Paraná e Santa Catarina (Brade, 1964; Sehnem, 1972; Paula, 1993 e Prado, 1989).

Material examinado: BRASIL. Pernambuco: São Vicente Férrer, Complexo da Serra do Mascarenhas, Mata do Estado, ca. 35 30'00'W07³5'00'S, ca. 650-750 m alt., Mata do Brejinho, 28/V/1998, Pietrobom-Silva 4301 (UFP; PEUFR; HB; SPF; MBM; SP; HBR; SJRP; BHCB); idem, Mata do Caidor, 22/VI/1988, Pietrobom-Silva 4366 (UFP); idem, 17/VIII/ 1998, Pietrobom-Silva 4402 (UFP; PEUFR; HB; SJRP; SP; SPF; MBM; BHCB; HBR).

\section{Doryopteris multipartita (Fée) Tryon, Contr.} Gray Herb. 143: 38. 1942.

Fig. 12-13

A espécie difere das outras estudadas pelo pecíolo nigrescente; lâmina foliar cartácea a subcoriácea; ala da raque entre o primeiro e o segundo segmento cuneiforme estreitado para baixo; costas e cóstulas evidentes até quase o ápice dos segmentos e lobos; e pelo segmento central pinatífido.

Na Mata do Estado foi coletado em um único ponto da área, crescendo sobre rocha humosa na encosta, interior da mata; formando pequena população com um único exemplar observado nas proximidades. Vive em ambientes onde aparece associada com Pecluma pectinata (L.) Price, Trichomanes krausii Hook. et Grév. e Asplenium serratum L..

Distribuição geográfica: Guiana, Bolívia, Paraguai e Argentina; no Brasil ocorre nos estados do Ceará, Pernambuco, Mato Grosso, Rio de Janeiro, São Paulo, Paraná, Santa Catarina e Rio Grande do Sul (Sehnem, 1972).

Material examinado: BRASIL. Pernambuco: São Vicente Férrer, Complexo da Serra do Mascarenhas, Mata do Estado, ca. 35³0'00’W- 
$07^{\circ} 35^{\prime} 00^{\prime}$ 'S, ca. 650-750 m alt., Mata do Brejinho, 28/V/1998, Pietrobom-Silva 4312 (UFP; HB; MBM).

3. Doryopteris pedata (L.) Fée, Gen. Fil. 133. 1850-52.

Fig. 14-15

A espécie difere das outras estudadas pelo pecíolo nigrescente; lâminas foliares coriáceas; ala da raque entre o primeiro e o segundo segmento conforme (não estreitado para baixo); costa e cóstulas não ultrapassando a metade dos segmentos e lobos, cobertos pelo tecido laminar e pelo segmento central inteiro.

Foi coletada em um único ponto da área, crescendo sobre rochas, entre vegetação do tipo rupestre, formando poucas populações com alguns indivíduos espalhados. Vive em ambientes onde aparece associada com Selaginella potarosensis Jenmam, Dicranoglossum desvauxii (Klotzch) Proctor, Anemia villosa H.B. \& Willd. e Polypodium triseriale Sw.

Distribuição geográfica: Grandes Antilhas, São Tomás e Ilhas Virgens; no Brasil, ocorre nos estado do Ceará e Pernambuco (Sehnem, 1972 e Paula, 1993).

Material examinado: BRASIL. Pernambuco: São Vicente Férrer, Complexo da Serra do Mascarenhas, Mata do Estado, ca. $35^{\circ} 30^{\prime} 00^{\prime \prime} \mathrm{W}$ 07 $35^{\prime} 00^{\prime}$ 'S, ca. 650-750 m alt., Mata do Caidor, 16/IX/1998, Pietrobom-Silva 4413 (UFP; PEUFR; HB; SPF; MBM; SP; BHCB; HBR); idem, 29/I/1999, Pietrobom-Silva 4509 (UFP).

4. Doryopteris varians (Raddi) J. Sm., Job. 4: 163.1841.

Fig. 16-17

Segundo Sehnem (1972), Doryopteris varians é caracterizada pela pouca segmentação das lâminas, mais ou menos em estrela de cinco pontas com a parte da palma larga, pelos pecíolos cilíndricos e negros um pouco tortuosos; e difere das outras espécies estudadas pelo pecíolo castanho; lâminas foliares férteis com 3-7 segmentos primários, segmento central inteiro e pelas costas e cóstulas glabras no lado abaxial da lâmina.

Foi encontrada em um único ponto da área, formando pequena população com único exemplar observado nas proximidades. Vive em ambientes onde aparece associada com Pecluma ptilodon (Kunze) Price, Trichomanes hymenoides Hedw. e Asplenium serratum L.

Distribuição geográfica: Guiana; no Brasil ocorre nos estados de Pernambuco, Minas Gerais, Rio de Janeiro, Paraná e Santa Catarina (Sehnem, 1972).

Material examinado: BRASIL. Pernambuco: São Vicente Férrer, Complexo da Serra do Mascarenhas, Mata do Estado, ca. $35^{\circ} 30^{\prime} 00^{\prime \prime} \mathrm{W}$ 07³5'00’'S, ca. 650-750 m alt., Mata do Caidor, 05/X/1998, Pietrobom-Silva 4430 (UFP; PEUFR; HB; MBM; HBR).

Figuras 9-17. Doryopteris collina: 9. Fronde; 10. rizoma e porção basal do pecíolo; 11 . porção do segmento evidenciando padrão de venação (Pietrobom-Silva 4301). Doryopteris multipartita: 12. hábito; 13. porção do segmento evidenciando o padrão de venação (PietrobomSilva 4312). Doryopteris pedata: 14. hábito; 15. porção do segmento evidenciando padrão de venação (Pietrobom-Silva 4413). Doryopteris varians: 16 . hábito; 17. porção do segmento evidenciando padrão de venação (PietrobomSilva 4430).

\section{Adiantum L.}

O gênero é caracterizado pelos esporângios ocorrerem sob um indúsio retroflexo, pelos pecíolos eretos, escuros e lustrosos e pínulas desmidiadas (Moran et al., 1995). Gênero Pantropical, amplamente distribuído, exceto em regiões com clima extremamente frio ou seco, com ca. 150 espécies (Tryon \& Tryon, 1982). $\mathrm{Na}$ área estudada foram registradas nove espécies e, todas foram coletadas como terrícolas de solo humoso junto de regato, nas encostas e margens de trilhas do interior da mata, formando poucas a várias populações ou mesmo, como 


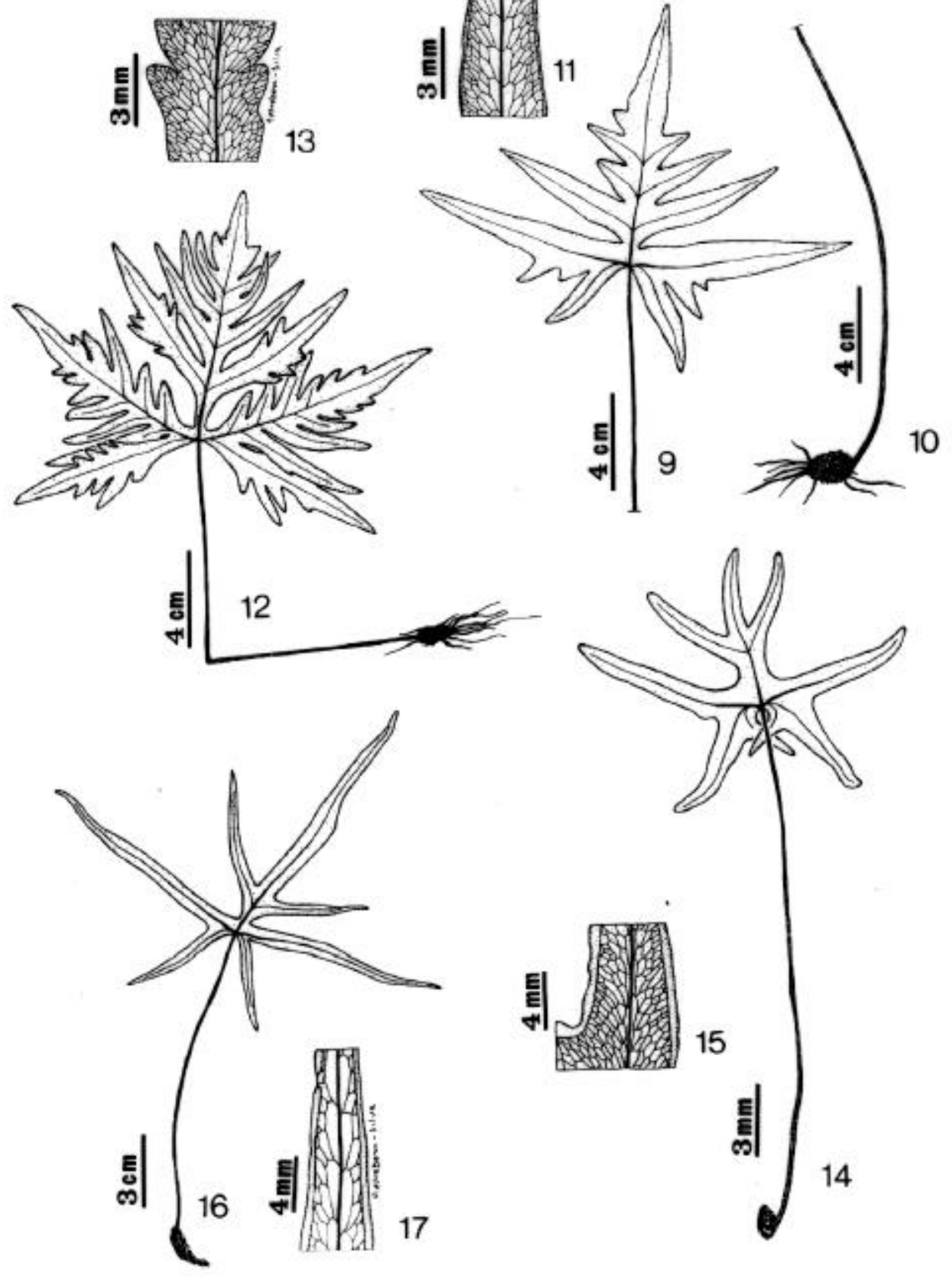

Figuras 9-17. Doryopteris collina: 9. Fronde; 10. rizoma e porção basal do pecíolo; 11. porção do segmento evidenciando padrão de venação (Pietrobom-Silva 4301). Doryopteris multipartita: 12. hábito; 13. porção do segmento evidenciando o padrão de venação (Pietrobom-Silva 4312). Doryopteris pedata: 14. hábito; 15. porção do segmento evidenciando padrão de venação (Pietrobom-Silva 4413). Doryopteris varians: 16. hábito; 17. porção do segmento evidenciando padrão de venação (Pietrobom-Silva 4430). 
indivíduos isolados. Ambrósio \& Barros (1997) registraram sobre barrancos úmidos nas bordas e no interior da mata espécies de Adiantum, em pequenas ou grandes populações ou ainda, indivíduos isolados.

1. Adiantum dioganum Glaz. \& Bak., Job. 310. 1882.

Fig. 18-19.

A espécie é caracterizada pelos rizomas levemente curtos a médio-rastejantes e pelas pínulas (23-)25-26 pares, as inferiores reduzidas, as medianas alongado-rombóideas, com a margem basioscópica reta a levemente falcada, margem acroscópica reta a levemente côncava e pelos soros 7-8(-10) por pínula.

Foi coletada em dois pontos da área, crescendo como terrestre de solo humoso junto de regato e na encosta no interior da mata, com indivíduos isolados e espalhados. $\mathrm{Na}$ área estudada vive em ambientes próxima de Adiantum obliquum Willd., Adiantum terminatum Kunze \& Miq., Adiantum latifolium Lam., Diplazium cristatum (Desr.) Alston e Ctenitis distans (Brack.) Ching. Distribuição geográfica: Espécie endêmica do Brasil nos estados de Pernambuco, Alagoas Minas Gerais, São Paulo e Paraná (Prado, 2000). Material examinado: BRASIL. Pernambuco: São Vicente Férrer, Complexo da Serra do Mascarenhas, Mata do Estado, ca. $35^{\circ} 30^{\prime} 00^{\prime \prime} \mathrm{W}$ 07 35'00'S, ca. 650-750 m alt., Mata da Pimenta, 31/III/1998, Pietrobom-Silva 4217 (UFP; PEUFR; HB; SPF; SP; HBR); idem, Mata do Caidor, 30/X/1998, Pietrobom-Silva 4461 (UFP; HB; SP); idem, Mata da Pimenta, 30/X/1998, Pietrobom-Silva 4474 ( UFP; HB; SP).

2. Adiantum dolosum Kunze, Linn. 21: 219. 1848.

Fig. 20-21

A espécie é caracterizada pelas frondes pinadas, pinas 5-7 pares, com soros únicos (cenosoros) marginais. Segundo Sehnem (1972) caracteriza-se pela cor verde-oliva das lâminas foliares e pelas pinas com vênulas anastomosadas.

Foi coletada em vários pontos da área, crescendo sobre solo humoso pelas encostas e margens de trilhas do interior da mata. Formando várias populações, principalmente nas margens das trilhas, ou indivíduos isolados nas encostas. Vive em ambientes onde aparece associada com várias espécies dos gêneros Adiantum, Ctenitis, com Danaea elliptica J. Sm. e Anemia hirta (L.) Sw. nas margens das trilhas.

Distribuição geográfica: América Central, Colômbia, Venezuela, Guianas e Suriname (Moran et al., 1995); no Brasil ocorre nos estados do Amazonas, Ceará, Pernambuco, Alagoas, Bahia e São Paulo (Sehnem, 1972 e Paula, 1993). Material examinado: BRASIL Pernambuco: São Vicente Férrer, Complexo da Serra do Mascarenhas, Mata do Estado, ca. $35^{\circ} 30^{\prime} 00^{\prime \prime} \mathrm{W}$ 07³5'00'S, ca. 650-750 m alt., Mata da Pimenta, 31/III/1998, Pietrobom-Silva 4208 (SP); idem, 31/III/1998, Pietrobom-Silva 4221 (UFP; PEUFR; HB; MBM; SP; HBR); idem, Mata do Brejinho, 22/VI/1998, Pietrobom-Silva 4370 (HB; SP).

3. Adiantum humile Kunze, Linn. 9: 80. 1834. Fig. 22-23

Plantas terrestres. Rizomas levemente curtos a médio-rastejantes, providos de escamas estreitamente triangulares, denticuladas, clatradas. Frondes $54-90 \mathrm{~cm}$ longas; estipes 30,5$50 \mathrm{~cm}$ longos, castanho-escuros a negros, lustrosos, com escamas densas, patentes; raques escamosos como o estipe; lâminas foliares 14,5$40 \mathrm{~cm}$ longas, oblongas, bipinadas, glabras, com bandas de idioblastos, esparsamente pilosas na face abaxial a glabras; pinas 2 pares, alternas 9$15 \mathrm{~cm}$ longas, oblanceoladas, segmento terminal lobado ou inciso sobre as margens superiores; pínulas 16-17 pares, diminuindo até a base, retangular-oblongas, fracamente falcadas, dimidiadas, subsésseis ou curtamente pecioladas; segmentos estéreis uniformes e marcadamente 
serrulados ao longo das margens acroscópicas e distais; venação livre, furcada. Soros 11-12(15) por segmentos, sobre a margem acroscópica e em torno do ápice até a metade da margem basioscópica; esporos triletes.

A espécie é caracterizada pelos rizomas levemente curtos a médio-rastejantes; pínulas 1617 pares; soros 11-12(-15) por segmentos, sobre a margem acroscópica e em torno do ápice até a metade da margem basioscópica.

Foi coletada em apenas um único ponto da área, crescendo sobre solo humoso, na margem da trilha em encosta do interior da mata, com poucos indivíduos aproximados e escassos.

Adiantum humile é apresentada como sendo a primeira referência para o estado de Pernambuco.

Distribuição geográfica: Belize, Panamá, Trinidad, Colômbia, Venezuela, Guianas, Equador e Peru (Moran et al., 1995).

Material examinado: Brasil, Pernambuco, São Vicente Férrer, Complexo da Serra do Mascarenhas, Mata do Estado, ca. 35³0'00’'W07³5'00'S, ca. 650-750 m alt., Mata da Pimenta, 24/VI/1998, Pietrobom-Silva 4362 (UFP; PEUFR; HB; SP; MBM).

\section{Adiantum latifolium Lam., Enc. 1. 43. 1783.} Fig. 24-25

Segundo Tryon \& Stolze (1989) é caracterizada pelas frondes bipinadas, os segmentos glaucos abaxialmente e a margem da lâmina estéril fina e igualmente serreada. De acordo com Moran, Zimmer \& Jermy (1995) pode haver híbridos entre $A$. latifolium (bipinado) e $A$. petiolatum (pinado), que são intermediários quanto à forma da fronde, geralmente com dois pares de pinas curtamente pinadas, a base da pina terminal alargada.

Foi coletada em alguns pontos da área como nas encostas e margens da trilha do interior da mata crescendo sobre solo humoso e formando pequenas populações com indivíduos escassos e aproximados. Vive em ambientes onde aparece associada com várias outras espécies do gênero Adiantum, Saccoloma elegans Kaulf., Ctenitis distans (Brack.) Ching, Blechnum occidentale L., Diplazium striatum (L.) Presl, Thelypteris nephrodioides (Klotzch) Proctor, Adiantopsis radiata (L.) Fée, Pteris denticulata var. denticulata Sw., Campyloneurum repens (Aubl.) Presl e Polypodium fraxinifolium Jacq. Distribuição geográfica: México, América Central, Antilhas, Trinidad, Colômbia, Venezuela, Guiana, Equador, Peru, Bolívia e Paraguai (Moran et al., 1995); no Brasil ocorre nos estados do Ceará, Paraíba, Pernambuco e Alagoas (Paula, 1993).

Material examinado: BRASIL. Pernambuco: São Vicente Férrer, Complexo da Serra do Mascarenhas, Mata do Estado, ca. 35 30'00'W07³5'00'S , ca. 650-750 m alt., Mata do Caidor, 20/IV/1998, Pietrobom-Silva 4258 (UFP; PEUFR; HB; SP; MBM; BHCB); idem, Mata da Pimenta, 20/IV/1998, Pietrobom-Silva 4265 (UFP; PEUFR; HB; SP; BHCB); idem, 30/X/ 1998, Pietrobom-Silva 4467 (UFP; HB; SP); idem, 30/X/1998, Pietrobom-Silva 4473 (UFP; $\mathrm{HB}$; SP).

5. Adiantum obliquum Willd., Sp. Pl. 5: 429. 1810.

Fig. 26-27

De acordo com Windisch (1983), é uma espécie próxima de Adiantum petiolatum, da qual difere principalmente pelos segmentos verdes, geralmente brilhantes, pelas porções estéreis com margens irregularmente serreadas, rizomas com escamas adpressas e soros de número e forma variada, menos de 18 por segmentos, em todas as margens acroscópicas e basioscópicas.

Foi coletada em um único ponto da área crescendo sobre solo humoso na encosta do interior da mata; observados poucos indivíduos isolados. Vive em ambientes crescendo próxima de $A$. diogoanum Glaz. \& Bak., A. terminatum 


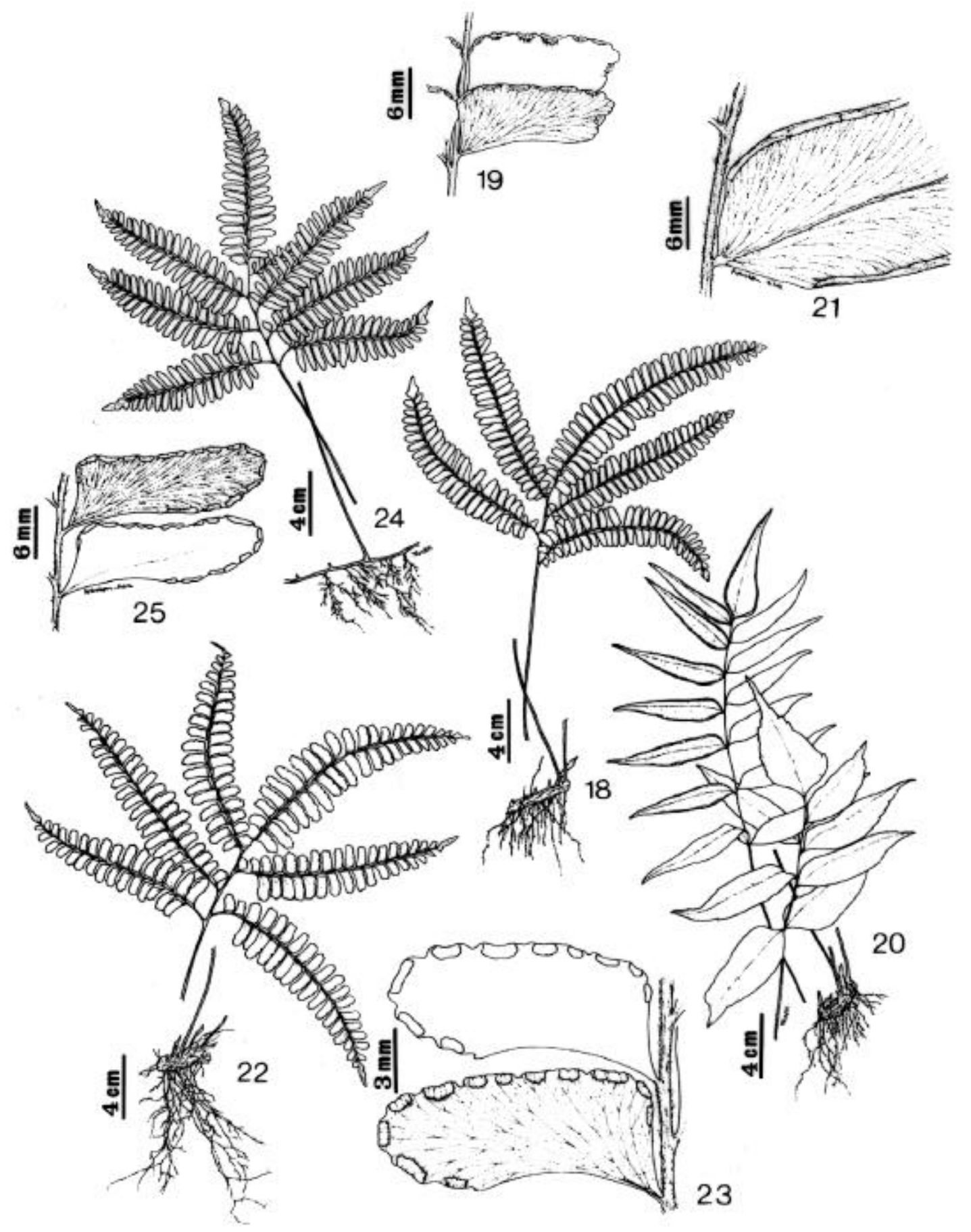

Figuras 18-25. Adiantum dioganum: 18. hábito; 19. disposição das pínulas na raquíola, padrão de venação e soros marginais (Pietrobom-Silva 4217). Adiantum dolosum: 20. hábito; 21. Pina mediana evidenciando padrão de venação e disposição dos soros (Pietrobom-Silva 4353). Adiantum humile: 22. hábito; 23. pina mediana evidenciando padrão de venação e disposição dos soros (Pietrobom-Silva 4362). Adiantum latifolium: 24. hábito; 25. pina mediana evidenciando padrão de venação e disposição dos soros (Pietrobom-Silva 4258). 
Kunze \& Miq., Diplazium cristatum (Desr.) Alston e Ctenitis distans (Brack.) Ching. Distribuição geográfica: Sul do México, América Central, Antilhas, Colômbia, Venezuela, Guiana, Equador, Peru e Bolívia (Moran et al., 1995); no Brasil ocorre nos estados do Amazonas, Ceará, Pernambuco, Bahia, Mato Grosso, Goiás, Rio de Janeiro e São Paulo (Sehnem, 1972 e Paula, 1993).

Material examinado: BRASIL. Pernambuco: São Vicente Férrer, Complexo da Serra do Mascarenhas, Mata do Estado, ca. 35 30'00'”W07³5'00's, ca. 650-750 m alt., Mata da Pimenta, 30/X/1998, Pietrobom-Silva 4472 (HB).

6. Adiantum petiolatum Desv., Berl. Mag. 5. 326. 1811.

Fig. 28-30

De acordo com Tryon \& Stolze (1989) uma das variedades de $A$. petiolatum possui raque glabra; pode ser distinguida das outras espécies pela lâmina foliar pinada, com pina alongada e margens estéreis eventualmente serreadas; plantas de $A$. petiolatum com a lâmina foliar bipinada podem ser híbridas com $A$. latifolium; difere das outras espécies estudadas pelos segmentos geralmente glaucos na superfície abaxial, opacos; soros 18-19(-22) por pina, sobre a margem acroscópica e em torno do ápice até a metade da margem basioscópica.

Foi coletada em apenas um ponto da área, crescendo em barranco próximo de regato; formando poucas populações com indivíduos escassos. Vive em ambientes onde aparece associada com Lomariopsis japurensis (Mart.) J. Sm., Thelypteris biolleyi (Christ.) Proctor, Thelypteris macrophylla (Kunze) Morton, Ctenitis distans (Back.) Ching, Campyloneurum phyllitidis (L.) Presl, Diplazium expansum Willd., Alsophilla sternbergii (Sternb.) Conant, Diplazium cristatum (Desv.) Alston e Lindsaea lancea var. lancea (L.) Bedd.

Distribuição geográfica: Sul do México, América Central, Antilhas, Trinidad e Tobago, Colômbia,
Venezuela, Guiana, Equador, Peru e Bolívia (Moran et al., 1995); no Brasil ocorre nos estados do Amazonas, Ceará, Pernambuco, Mato Grosso, Rio de Janeiro e Santa Catarina (Sehnem, 1972).

Material examinado: BRASIL. Pernambuco: São Vicente Férrer, Complexo da Serra do Mascarenhas, Mata do Estado, ca. 35 30'00’'W07³5'00’'S, ca. 650-750 m alt., Mata do Caidor, 20/IV/1998, Pietrobom-Silva 4244 (HB; SP).

7. Adiantum pulverulentum L., Sp. Pl. 2. 1096. 1753.

Fig. 31-34

De acordo com Moran et al., (1995), é caracterizada pelas frondes bipinadas e os segmentos com cenosoro marginal (raramente 2). Segundo Lellinger (1991), esta espécie é mais próxima de $A$. villosum L., cujos soros se estendem até o ápice da pínula e continua na margem distal. Difere das outras espécies estudadas pelos rizomas curto-rastejantes; soros um pôr segmento e pínulas com 40-41 pares.

Foi coletada em dois pontos da área, crescendo sobre solo humoso na encosta próximo da trilha e em barranco de regato, junto de plantações de banana. Em ambos os pontos, apresenta-se como indivíduos isolados. Vive em ambientes onde aparece associada com Lomagramma guianensis (Aubl.) Ching e com outras espécies de pteridófitas, esporádica nas encostas das trilhas do regato; geralmente vive associada com Pityrogramma calomelanos (L.) Link, Selaginella potaroensis Jenman e Thelypteris hispidula (Decne.) Reed.

Distribuição geográfica: México, América Central, Antilhas e Trinidad, Venezuela, Guiana, Equador, Peru e Bolívia (Moran et al., 1995); no Brasil ocorre nos estados do Ceará, Pernambuco, Alagoas, Bahia, Goiás, Minas Gerais, Rio de Janeiro, São Paulo e Rio Grande do Sul (Sehnem, 1972 e Paula, 1993).

Material examinado: BRASIL. Pernambuco: São Vicente Férrer, Complexo da Serra do 


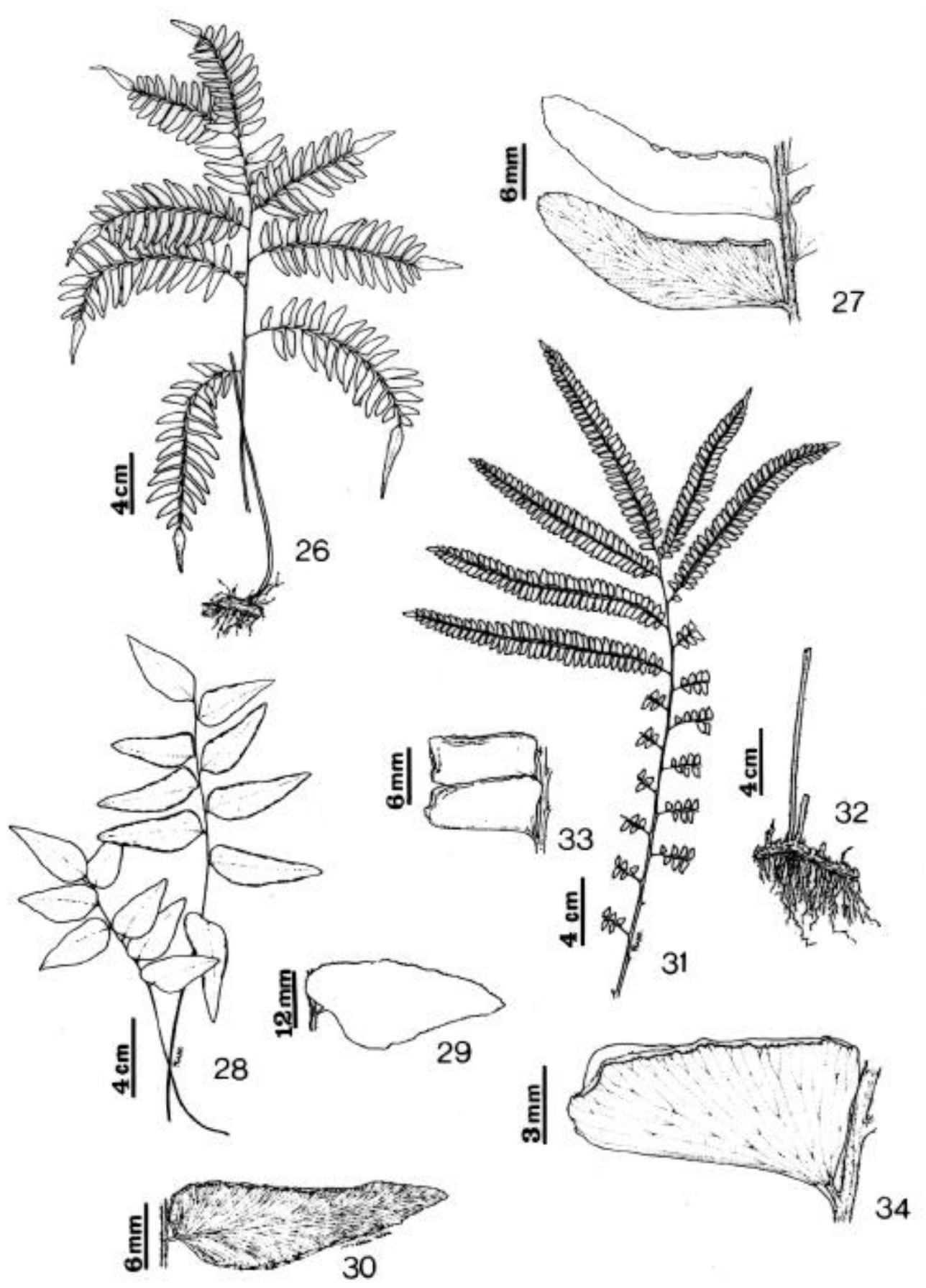

Figuras 26-34. Adiantum obliquum: 26. hábito; 27. disposição da pina na raque; pina evidenciando padrão de vehação e soros (Pietrobom-Silva 4472).Adiantum petiolatum: 28. hábito; 29. pina estéril; 30. pina fértil evidenciando padrão de venação e soros (Pietrobom-Silva 4244). Adiantum pulverulentum: 31. parte da fronde; 32. rizoma e porção basal do estipe; 33. disposição das pínulas na raque (Pietrobom-Silva 4363); 34. pina mediana evidenciando padrão de venação e soro (Pietrobom-Silva 4273). 
Mascarenhas, Mata do Estado, ca. 35³0'00”W07³5'00”'S, ca. 650-750 m alt., Mata do Caidor, 24/VI/1998, Pietrobom-Silva 4363 (SP; UFP); idem, 05/X/1998, Pietrobom-Silva 4431 (HB; $\mathrm{SP})$.

8. Adiantum terminatum Kunze \& Miq., Diar. Inst. Reg. Bat. 3. 1843.

Fig. 35-37

Segundo Tryon \& Stolze (1989), esta espécie é caracterizada geralmente pelos vários indúsios nos segmentos férteis, pina apical gradualmente reduzida, tricomas longos e simples localizados na face abaxial das pínulas. Distingue-se das outras espécies estudadas pelos rizomas curtorastejantes; soros 9-10 por segmento e pínulas com 17-19 pares.

Foi coletada em dois pontos da área, crescendo sobre solo humoso da encosta e margem de trilha na encosta, no interior da mata formando pequenas populações de alguns indivíduos aproximados ou isolados. Vive em ambientes onde aparece associada, na margem da trilha na encosta, como Adiantum tetraphyllum H.B. \& Willd., Adiantum pulverulentum L., Pteris denticulata var. denticulata Sw., Lygodium venustum Sw., Danaea elliptica J. Sm., Adiantum dolosum Kunze, Ctenitis distans (Brack.) Ching; como também, com outras espécies de pteridófitas pelas proximidades, Adiantum dolosum Kunze, Ctenitis distans (Brack.) Ching, Adiantum latifolium Lam., Adiantum obliquum Willd. e Thelypteris hispidula (Decne.) Reed.

Distribuição geográfica: Sul do México, América Central, Trinidad, Colômbia, Venezuela, Guiana, Equador, Peru e Bolívia (Moran et al., 1995); no Brasil ocorre nos estados do Ceará, Pernambuco, Alagoas, Bahia, Mato Grosso, São Paulo e Paraná (Sehnem, 1972).

Material examinado: BRASIL. Pernambuco: São Vicente Férrer, Complexo da Serra do Mascarenhas, Mata do Estado, ca. 35³0'00'”W07³5'00”S, ca. 650-750 m alt., Mata da
Pimenta, 20/IV/1998, Pietrobom-Silva 4232 (UFP; PEUFR; HB; SP); idem, 30/X/1998, Pietrobom-Silva 4466 (HB; UFP; SP); idem, 30/X/1998, Pietrobom-Silva 4468 (UFP; SP).

9. Adiantum tetraphyllum H.B. \& Willd., Sp. P1. 5: 441. 1810.

Fig. 38-41

De acordo com Windisch (1983), Adiantum tetraphyllum é caracterizada pela porção distal das pínulas estéreis geralmente arqueadas e com os segmentos vizinhos muito reduzidos. Distingue-se das outras espécies estudadas pelos rizomas curto-rastejantes; soros 5-7 por segmentos, sobre a margem acroscópica e, ocasionalmente sobre a porção dista; pínulas com 23-25 pares.

Foi coletada em vários pontos da área, crescendo sobre solo humoso pelas encostas do interior da mata, formando geralmente pequenas populações com indivíduos escassos. Podendo ser encontrados indivíduos isolados em barrancos junto de regatos no interior da mata. Vive em ambientes onde aparece associada com Adiantum latifolium Lam., Thelypteris biolleyi (Crist) Proctor, Ctenitis distans (Brack) Ching, Triplophyllum funestum (Kunze) Holttum, Adiantum dolosum Kunze, Adiantopsis radiata (L.) Fée, nos ambientes de encostas.

Distribuição geográfica: Sul do México, América Central, Antilhas, Trinidad, Guiana, Equador, Peru, Bolívia e Paraguai (Moran et al., 1995 e Tryon \& Stolze, 1989); no Brasil, ocorre nos estados do Amazonas, Ceará, Pernambuco, Mato Grosso, Rio de Janeiro e Santa Catarina (Sehnem, 1972 e Paula, 1993).

Material examinado: BRASIL. Pernambuco: São Vicente Férrer, Complexo da Serra do Mascarenhas, Mata do Estado, ca. 35 30'00'W07³5'00'S, ca. 650-750 m alt., Mata do Brejinho, 28/V/1998, Pietrobom-Silva 4328 (UFP; PEUFR; HB; SPF; BHCB; MBM; SP; HBR; SJRP); idem, Mata do Caidor, 05/X/1998, Pietrobom-Silva 4441 (HB; SP); idem, 30/X/ 

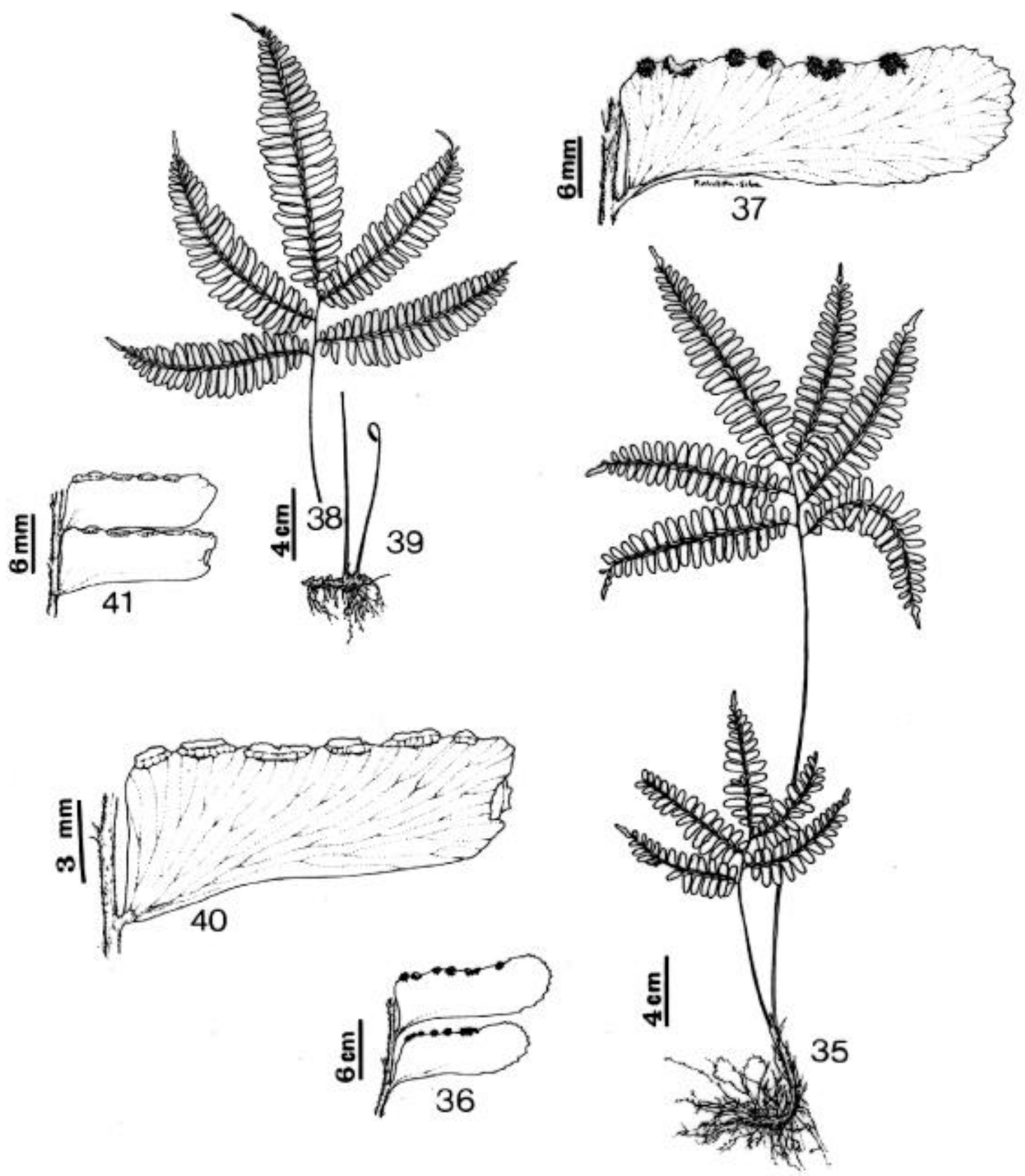

Figuras 35-41. Adiantum terminatum: 35. hábito; 36. disposição das pínulas na raque; 37. pina mediana evidenciando padrão de venação e soros (Pietrobom-Silva 4468). Adiantum tetraphyllum: 38. parte da fronde; 39. rizoma e porção basal do estipe; 40. pina mediana evidenciando padrão de venação e soros; 41. disposição das pínulas na raque (PietrobomSilva 4328). 
1998, Pietrobom-Silva 4454 (UFP; HB; SP); idem, 30/X/1998, Pietrobom-Silva 4455 (UFP; HB; SP); idem, 30/X/1998, Pietrobom-Silva 4457 (UFP; HB; SP).

Figuras 18-25. Adiantum dioganum: 18. hábito; 19. disposição das pínulas na raquíola, padrão de venação e soros marginais (Pietrobom-Silva 4217). Adiantum dolosum: 20. hábito; 21. Pina mediana evidenciando padrão de venação e disposição dos soros (Pietrobom-Silva 4353). Adiantum humile: 22. hábito; 23. pina mediana evidenciando padrão de venação e disposição dos soros (Pietrobom-Silva 4362). Adiantum latifolium: 24. hábito; 25. pina mediana evidenciando padrão de venação e disposição dos soros (Pietrobom-Silva 4258).

Figuras 26-34. Adiantum obliquum: 26. hábito; 27. disposição da pina na raque; pina evidenciando padrão de venação e soros (Pietrobom-Silva 4472).Adiantum petiolatum: 28. hábito; 29. pina estéril; 30. pina fértil evidenciando padrão de venação e soros (PietrobomSilva 4244). Adiantum pulverulentum: 31. parte da fronde; 32 . rizoma e porção basal do estipe; 33. disposição das pínulas na raque ( $P i$ etrobom-Silva 4363); 34. pina mediana evidenciando padrão de venação e soro (Pietrobom-Silva 4273).

Figuras 35-41. Adiantum terminatum: 35. hábito; 36. disposição das pínulas na raque; 37. pina mediana evidenciando padrão de venação e soros (Pietrobom-Silva 4468). Adiantum tetraphyllum: 38. parte da fronde; 39. rizoma e porção basal do estipe; 40. pina mediana evidenciando padrão de venação e soros; 41. disposição das pínulas na raque (PietrobomSilva 4328).

\section{Pteris L.}

O gênero é caracterizado pelas frondes 1-4 pinadas, pelos padrões de ramificação das pinas basais, soros marginais contínuos e paráfises entre os esporângios (Moran, 1995c). Gênero pantropical a subtropical com ca. 200 espécies, destas, 55 ocorrem na América (Tryon \& Tryon, 1982).
$\mathrm{Na}$ área estudada foram registradas três espécies, crescendo sobre solo humoso, em barrancos ao longo de regatos ou na encosta, no interior da mata, formando sempre pequenas populações, com poucos indivíduos, espalhados ou isolados. Santos \& Barros (1999) referem seus espécimens, crescendo nas encostas do interior das matas e Prado \& Windisch (2000) registraram a ocorrência de espécies de Pteris, no interior de matas úmidas e secas, margens de rios e córregos, em matas de galerias. Windisch (1983), para a Serra Ricardo Franco, registrou como terrestre nas matas de encosta, e ainda, Paula (1993) registrou espécies de Pteris no interior de matas, próximo à cursos d'água ou ainda nas encostas de vales e serras.

\section{Pteris biaurita L., Sp. Pl. 2. 1076. 1753.}

Fig. 42-44

De acordo com Tryon \& Stolze (1989), é caracterizada pelas aréolas somente ao longo das costas e pelo par de pina basal com uma pínula basioscópica, pinatisecta. Difere de $P$. leptophylla pelo par basal furcado e presença de lacínios na base da cóstula na face adaxial da pina (Prado \& Windisch, 2000).

Foi coletada em um único ponto da área, crescendo sobre solo humoso, em barranco ao longo de regato do interior da mata; observado uma única vez com apenas dois indivíduos. Vive em ambientes onde aparece associada com várias espécies de pteridófitas, como Asplenium laetum Sw., Asplenium otites Link., Diplazium striatum (L.) Presl, Didymochlaena truncatula (Sw.) J. Sm., Blechnum occidentale L., Lomagramma guianensis (Aubl.) Ching, Lomariopsis japurensis (Mart.) J. Sm. e Cyclodium heterodon (Schrad.) Moore var. abbreviatum (Presl) A.R. Sm..

Distribuição geográfica: Sul do México, América Central, Antilhas, Colômbia, Venezuela, Guiana, Equador, Peru e Bolívia (Moran, 1995c); no Brasil, ocorre nos estados do Amazonas, Pará, Ceará, Pernambuco, Alagoas, Goiás, Minas 
Gerais e Rio de Janeiro (Sehnem, 1972; Paula, 1993 e Prado \& Windisch, 2000).

Material examinado: BRASIL. Pernambuco: São Vicente Férrer, Complexo da Serra do Mascarenhas, Mata do Estado, ca. 35 30'00'W07³5'00”S, ca. 650-750 m alt., Mata do Caidor, 28/V/1999, Pietrobom-Silva 4322 (UFP; HB; MBM; SP).

\section{Pteris denticulata var. denticulata Sw.,} Prod.: 129. 1788.

Fig. 45-48

De acordo com Prado \& Windisch (2000) Pteris denticulata Sw. var. denticulata é caracterizada pela raque alada em toda a sua extensão, as pinas basais variando de furcadas a pinatífidas no lado basioscópico e pela margem denticulada das pinas e segmentos; difere de $P$. denticulata Sw. var. tristicula pelas pinas basais furcadas a pinatífidas no lado basioscópico e pinas medianas e distais inteiras lanceoladas.

Foi coletada em dois pontos da área, como terrestre, sobre solo humoso, encosta no interior da mata, próximo do regato e da trilha; formando sempre pequena população com indivíduos isolados ou espalhados. Vive em ambientes onde aparece associada com Ctenitis distans (Brack.) Ching, Adiantum terminatum Kunze \& Miq., Polypodium fraxinifolium Jacq., Campyloneurum repens (Aubl.) C. Presl, Adiantopsis radiata (L.) Fée, Saccoloma elegans Kaulf. em ambiente próximo da trilha; como também, geralmente associada com Adiantum petiolatum Desv., Polybotrya cylindrica Kaulf., Lomariopsis japurensis (Mart.) J. Sm., Blechnum occidentale L. e Adiantopsis radiata (L.) Fée.

Distribuição geográfica: Sul do México, América Central, Colômbia, Venezuela, Guiana, Equador, Peru e Bolívia (Moran, 1995c); no Brasil, ocorre nos estados do Pará, Maranhão, Ceará, Pernambuco, Bahia, Mato Grosso Mato, Grosso do Sul, Espírito Santo, Rio de Janeiro, Minas Gerais, São Paulo, Paraná, Santa Catarina e Rio
Grande do Sul (Sehnem, 1972; Paula, 1993 e Prado \& Windisch, 2000).

Material examinado: BRASIL. Pernambuco: São Vicente Férrer, Complexo da Serra do Mascarenhas, Mata do Estado, ca. 35 30'00'W07³5'00'S, ca. 650-750 m alt., Mata da Pimenta, 20/IV/1998, Pietrobom-Silva 4231 (UFP; PEUFR; HB; SP; MBM); idem, 28/V/1999, Pietrobom-Silva 4329 (UFP; PEUFR; MBM; HBR).

3. Pteris leptophylla Sw., Vet. Ak. Handl.: 70. 1817.

Fig. 49-51

De acordo com Prado \& Windisch (2000), é caracterizada pela fronde bipinado-pinatífida; pela raque e raquíola alados e pelo padrão de venação parcialmente areolado, com aréolas junto a costa e cóstula e demais vênulas todas livres acima das aréolas; difere de $P$. biaurita pelas pinas basais pinado-pinatífidas e a ausência de lacínios na base da cóstula na face adaxial da pina.

Foi coletada em apenas um ponto da área, crescendo sobre rocha granítica humosa em barranco junto de regato; formando pequena população de indivíduos isolados ou aproximados. $\mathrm{Na}$ área estudada vive em ambientes onde aparece associada com Asplenium otites Link, Pecluma pectinata (L.) Price.

Distribuição geográfica: América do Sul; no Brasil, ocorre nos estados do Ceará, Pernambuco, Bahia, Minas Gerais, Espírito Santo, Rio de Janeiro, São Paulo e Santa Catarina (Sehnem, 1972 e Prado \& Windisch, 2000).

Material examinado: BRASIL. Pernambuco: São Vicente Férrer, Complexo da Serra do Mascarenhas, Mata do Estado, ca. 35 30'00'W07³5'00'S, ca. 650-750 m alt., Mata do Caidor, 16/IX/1998, Pietrobom-Silva 4420 (UFP; HB; SP); idem, 29/I/1999, Pietrobom-Silva 4511 (UFP; PEUFR; HB; MBM).

\section{Acrostichum L.}

O gênero é caracterizado pelas frondes 2,0-4,0m longas, pinadas, venação reticulada e 
esporângios com paráfises que cobrem toda a superfície abaxial da pina (Moran, 1995d). Gênero Pantropical de três ou mais espécies, sendo duas de ocorrência na América (Tryon \& Stolze, 1989). Representado na Mata do Estado por uma única espécie:

1. Acrostichum daneaefolium Langsd. \& Fisch., Ic. Fil. 5. t. 1. 1810.

Fig. 52-55

De acordo com Mickel \& Beitel (1988), Acrostichum danaeifolium é distinguida de $A$. aureum L. pelas pinas férteis por toda fronde, 40-60 pares pinas, aréolas junto da costa largas e paráfises com extremidades alongadas, pouco lobadas ou inteiras.

Foi coletada em vários pontos da área, crescendo em solos encharcados, próximo ou junto da margem do açude, ou ao longo dos regatos, na mata ciliar degradada, ensolarada; formando grandes populações com indivíduos agregados. Vive associada a Cyathea microdonta (Desv.) Domin, Blechnum serrulatum Rich., Thelypteris interrupta (Willd.) Iwats. e Thelypteris serrata (Cav.) Alston.

Distribuição geográfica: Sul da Flórida, México, América Central, Antilhas, Bermudas, Colômbia, Venezuela, Guiana, Equador, Peru, Bolívia e Paraguai (Moran, 1995d); no Brasil, ocorre nos estados de Pernambuco, Rio de Janeiro, São Paulo, Paraná, Santa Catarina e Rio Grande do Sul (Sehnem, 1972).

Material examinado: BRASIL. Pernambuco: São Vicente Férrer, Complexo da Serra do Mascarenhas, Mata do Estado, ca. 35³0'00’'W07³5'00'S, ca. 650-750 m alt., Mata do Brejinho, 20/IV/1998, Pietrobom-Silva 4262 (UFP; PEUFR; HB; SP); idem, 05/05/1999, PietrobomSilva 4539 (MBM).

Figuras 42-55. Pteris biaurita: 42. parte da fronde; 43. rizoma e porção basal do pecíolo; 44. porção do segmento evidenciando padrão de venação (Pietrobom-Silva 4322). Pteris denticulata var. denticulata: 45. parte da fronde; 46. rizoma e porção basal do pecíolo; 47. ápice da pina evidenciando margem denticulada (Pietrobom-Silva 4231); 48. porção do segmento evidenciando padrão de venação (Pietrobom-Silva 4394). Pteris leptophylla: 49. parte da fronde; 50. rizoma e porção basal do pecíolo (Pietrobom-Silva 4420); 51. porção do segmento evidenciando padrão de venação (Pietrobom-Silva 4511). Acrostichum danaeifolium: 52. ápice da fronde fértil; 53. porção da pina mediana evidenciando padrão de venação; 54. tricoma estrelado do tecido laminar, face abaxial; 55. paráfise (Pietrobom-Silva 4262).

\section{Conclusões}

A família Pteridaceae ocorre na Mata do Estado com a maior riqueza específica dentre todas as famílias estudadas por Silva (2000). O gênero com maior representatividade é Adiantum L. com nove espécies. As populações de Acrostichum danaeifolium são expressivas na Mata do Estado, ocorrendo em todos os pontos baixos e encharcados, com muitos indivíduos com porte de $2,50 \mathrm{~m}$ altura, principalmente na parte anterior da mata da Pimenta.

As espécies estudadas são, quanto a forma de vida, predominantemente hemicriptófitas sendo comumente encontradas em ambientes sombreados, próximos a cursos de regatos, barrancos e encostas.

\section{Agradecimentos}

Os autores agradecem ao Dr. Jefferson Prado pela revisão nas identificações e determinações de espécies do gênero Adiantum; a Coordenação de Aperfeiçoamento de Pessoal de Nível Superior (CAPES) pelo apoio financeiro ao primeiro autor; aos desenhistas Frank Valdomiro da Silva e Claudia Renata Siqueira, pela confecção das pranchas e ao Guillermo Gamarra Rojas, pela elaboração do Abstract. 


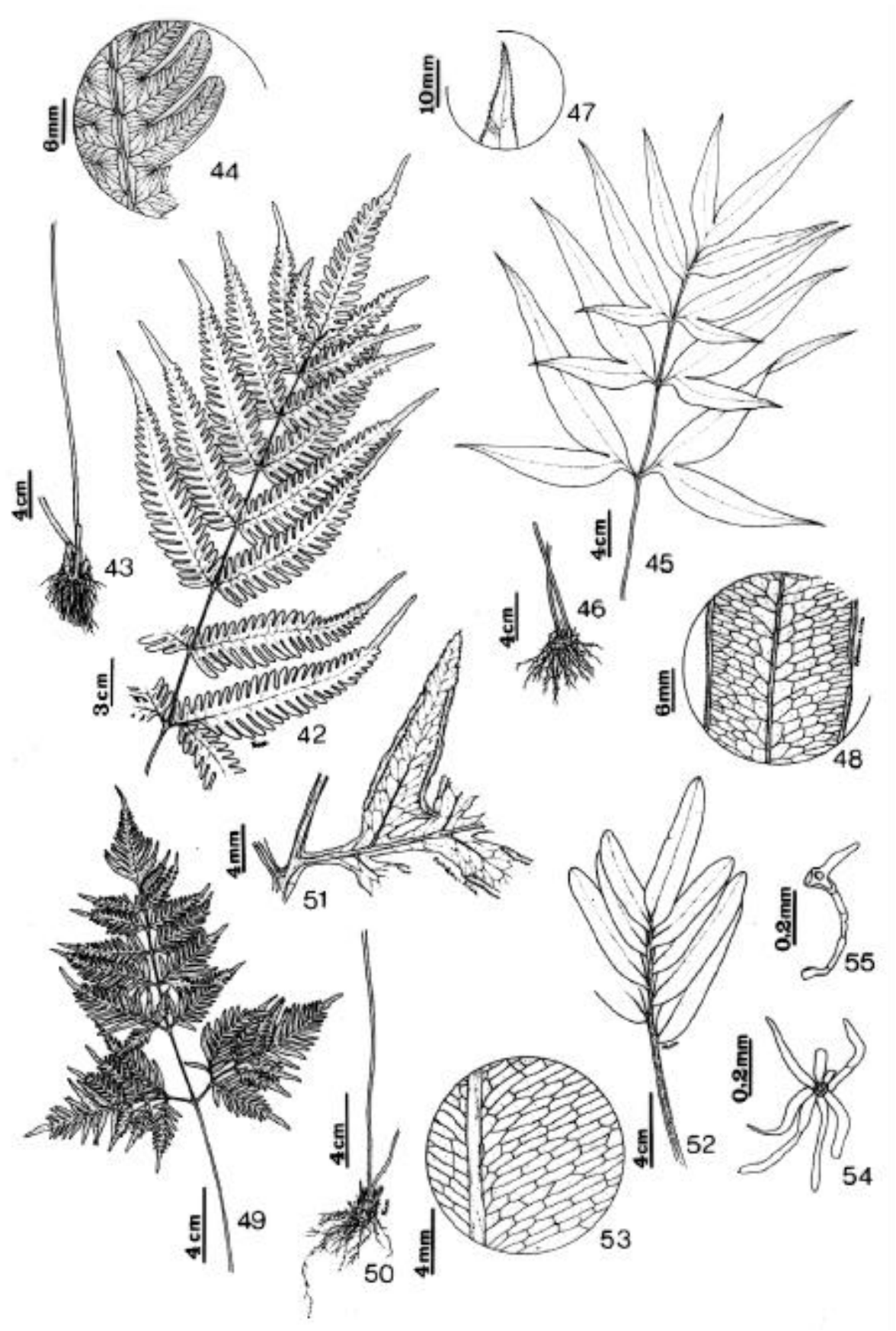

Figuras 42-55. Pteris biaurita: 42. parte da fronde; 43. rizoma e porção basal do pecíolo; 44. porção do segmento evidenciando padrão de venação (Pietrobom-Silva 4322). Pteris denticulata var. denticulata: 45. parte da fronde; 46. rizoma e porção basal do pecíolo; 47. ápice da pina evidenciando margem denticulada (Pietrobom-Silva 4231); 48. porção do segmento evidenciando padrão de venação (Pietrobom-Silva 4394). Pteris leptophylla: 49. parte da fronde; 50. rizoma e porção basal do pecíolo (Pietrobom-Silva 4420); 51. porção do segmento evidenciando padrão de venação (PietrobomSilva 4511). Acrostichum danaeifolium: 52. ápice da fronde fértil; 53. porção da pina mediana evidenciando padrão de venação; 54. tricoma estrelado do tecido laminar, face abaxial; 55. paráfise (Pietrobom-Silva 4262). 


\section{Referências bibliográficas}

Ambrósio, S. T. \& Barros, I. C. L. 1997. Pteridófitas de uma área remanescente de Floresta Atlântica do Estado de Pernambuco, Brasil. Acta Botanica Brasilica, Porto Alegre 11(2): 105-113.

Andrade-Lima, D. 1960. Estudos Fitogeográficos de Pernambuco. Instituto Pesquisa Agronômica, Recife (5): 305-341.

Andrade-Lima, D. 1969. Pteridófitas que ocorrem nas Floras Extra-Amazônica e Amazônica do Brasil e Proximidades. Pp. 34-39. In: Anais do XX Congresso Nacional de Botânica. Goiânia, 1969.

Barros, I. C. L. 1997. Pteridófitas ocorrentes em Pernambuco: Ensaio Biogeográfico e Análise Numérica. Tese Doutorado, Universidade Federal Rural de Pernambuco.

Barros, I. C. L. \& Fonseca, E. R. 1996. Lycopodiaceae Mirbel de "Brejo dos Cavalos" - Caruaru, Estado de Pernambuco. Boletim Sociedade Broteriana, Coimbra, sér. 2 67: 263-269.

Barros, I. C. L.; Fonseca, E. R.; Valdevino, J. A. \& Paula, E. L. 1996. Contribuição ao estudo taxonômico das pteridófitas ocorrentes na Reserva Ecológica de Caetés - Paulista, PE. Boletim Sociedade Broteriana, Coimbra sér. 2 67: 271-286.

Barros, I. C. L.; Santiago, A. C. P.; Xavier, S. R. S.; Pietrobom-Silva, M. R. \& Luna, C. P. L. 2001. Diversidade e Aspectos Ecológicos das pteridófitas (avencas, samambaias e plantas afins) ocorrentes em Pernambuco. In: SECTMA - Secretaria de Ciência, Tecnologia e Meio Ambiente (Ed.). Atlas de Biodiversidade de Pernambuco. No prelo.

Barros, I. C. L.; Silva, A. J. R. \& Lira, O. C. 1988. Distribuição geográfica das Pteridófitas ocorrentes no estado de Pernambuco, Brasil. Acta Botanica Brasilica, Porto Alegre 2(1-2): 47-84.

Barros, I. C. L.; Silva, A. J. R. \& Silva, L. L. S. 1989. Levantamento florístico das pteridófitas ocorrentes na Zona das Caatingas do estado de Pernambuco. Biologica Brasilica, Recife 1( 2): 143-159.

Bastos, C. C. C. \& Cutrin, M. V. J. 1999. Pteridoflora da Reserva Florestal do Csacavém, São Luis Maranhão. Bol Mus. Para. Emílio Goeldi, sér. Bot. 15(1): 3-37.

Brade, A. C. 1964. Contribuição paro o conhecimento das espécies brasileiras do gênero Doryopteris J. Sm. (Polypodiaceae). Arquivo Jardim Botânico do Rio de Janeiro, Rio de Janeiro 18: 39-72.
CONDEPE - Instituto de Planejamento de Pernambuco. 1990. Mapa - Classificação dos Solos e de sua capacidade de uso - Esc. 1:200.000 - Recife.

CPRH - Companhia Pernambucana de Controle da Poluição Ambiental e de Administração dos Recursos Hídricos. 1994. Projeto Piloto da Bacia Hidrográfica do Rio Goiana, Pernambuco. Macrozoneamento. Recife, Pernambuco.

Ferreira, M. F. A.; Rodal, M. J. N. \& Carvalho, G. H. de. 1985. Vegetação de Pernambuco. Pp. 245-249. In: Anais da VIII Reunião Nordestina de Botânica, Recife.

Fonseca, E. R. 1992. Pteridófitas da Reserva do Gurjaú, Cabo, Pernambuco. Dissertação de Mestrado, Universidade Federal de Pernambuco.

Graçano, D.; Prado, J. \& Azevedo, A. A. 1998. Levantamento preliminar de Pteridophyta do Parque Estadual do Rio Doce (MG). Acta Botanica Brasilica 12(2): 165-181.

Holmgren, P. K.; Holmgren, N. H. \& Barnett, L.C. 1990. Index Herbariorum, Part I: The Herbaria of the World. 8 ed. Int. Ass. Plant Taxonomy/New York Botanical Garden. 693 p.

Holttum, R. E. 1938. The ecology of tropical pteridophytes. Pp. 420-450. In: F. Veerdonrn (Ed.). Manual of Pteridology. The Hague Martinus Nijhoff, Amsterdan.

Kornás, J. 1993. The significance of historical factors and ecological preference in the distribuition of African pteridophytes. Journal of Biogeography 20: 81-286.

Kramer, K. U. \& Green, P. S. 1990. Pteridophytes and Gymnosperms Vol. I. In: K. Kubitzki (Ed.). The families and genera of vascular plants. SpringerVerlag, Berlin, $404 \mathrm{p}$.

Lellinger, D. B. 1991. Common and confusing bipinnate-dimidiate Adiantums of Tropical America. American Fern Journal 81(3): 99-102.

Mickel, J. T. \& Beitel, M. J. 1988. Pteridophyte Flora of Oaxaca. New York: The New York Botanical Garden, 568p.

Moran, R.C. 1995a. Pityrogramma Link. Pp. 137-140. In: G. Davidse et al. (Eds.). Flora Mesoamericana. Universidad Nacional Autónoma de México, México.

Moran, R.C. 1995b. Doryopteris Sm.. Pp. 129-131. In: G. Davidse et al. (Eds.). Flora Mesoamericana. Universidad Nacional Autónoma de México, México.

Moran, R.C. 1995c. Pteris L.. Pp. 140-144. In: G. Davidse et al. (Eds.). Flora Mesoamericana. 
Universidad Nacional Autónoma de México, México.

Moran', R.C. 1995d. Acrostichum L.. Pp. 105-106. In: G. Davidse et al. (Eds.). Flora Mesoamericana. Universidad Nacional Autónoma de México, México.

Moran, R. C. \& Riba, R. 1995. Psilotaceae a Salviniaceae Vol. I. In: G. Davidse et al. (Eds.). Flora Mesoamericana. Universidad Nacional Autónoma de México, México. 470 p.

Moran, R.C.; Zimer, B. \& Jermy, A. C. 1995. Adiantum L.. Pp. 106-117. In: G. Davidse et al. (Eds.). Flora Mesoamericana. Universidad Nacional Autónoma de México, México.

Mori, S. A.; Silva, L. A. M.; Lisboa, G. et al. 1989. Manual de manejo do herbário fanerogâmico. Ilhéus: Centro de Pesquisa do Cacau. 104 p.

Pacheco, L. 1995. Adiantopsis Fée. Pp. 106. In: G. Davidse et al. (Eds.). Flora Mesoamericana. Universidad Nacional Autónoma de México, México.

Page, C. N. 1979. The diversity of Ferns. An Ecological Perspective. Pp. 9-56. In: A. F. Dyer (Ed.). The experimental Biology of Ferns. Academic Press, London.

Paula, E. L. 1993. Pteridófitas da Serra do Baturité, Ceará. Dissertação de Mestrado. Universidade Federal de Pernambuco.

Pichi-Sermolli, R. E. G. 1996. Authors of Scintific names in Pteridophyta. Royal Botanical Gardens, Kew. $78 \mathrm{p}$.

Prado, J. 1989. Os Representantes da Família Pteridaceae, Subfamília Cheilantoideae (Div. Pteridophyta) ocorrentes nos Campos Rupestres da Cadeia do Espinhaço no Estado de Minas Gerais, Brasil. Dissertação de Mestrado. Universidade de São Paulo.

Prado, J. 1992. Flora da Serra do Cipó, Minas Gerais: Pteridaceae-Cheilanthoideae. Boletim Instituto Botânica 13: 141-159.

Prado, J. 1997. Flora da Serra do Cipó, Minas Gerais: Pteridaceae-Adiantoideae e Taenitidoideae. Boletim Instituto Botânica 16: 115-118.

Prado, J. 2000. A new species of Adiantum (Pteridaceae) from Bahia, Brazil. Brittonia 52(2): 210-212.

Prado, J. \& Windisch, P. G. 2000. The genus Pteris L. (Pteridaceae) in Brazil. São Paulo, Boletim Instituto Botânica 13: 103-199, 94 fig., 2 tab., 8 map.

Proctor, G. R. 1985. Ferns of Jamaica. A guide to the Pteridophytes. London: British Museum Natural History, 631p.
Ranker, T. A. 1995. Hemionitis L.. Pp. 131-133. In: G. Davidse et al. (Eds.). Flora Mesoamericana. Universidad Nacional Autónoma de México, México.

Rodal, M. J. N.; Sales, M. F. \& Mayo, S. J. 1998. Florestas Serranas de Pernambuco. Localização e Conservação do Remanescentes dos Brejos de Altitude. Recife: UFRPE, Imprensa Universitária, 25p.: il., 7 map.

Sales, M. F.; Mayo, S. J. \& Rodal, M. J. N. 1998. Plantas vasculares das Florestas Serranas de Pernambuco: Um Checklist da Flora Ameaçada dos Brejos de Altitude, Pernambuco, Brasil. Recife: Universidade Federal Rural de Pernambuco. Imprensa Universitária-UFRPE, 13.:il. 130p.

Santos, K. M. R. \& Barros, I. C. L. 1999. Pteridófitas das Matas do Bituri Grande, município de Brejo da Madre de Deus, estado de Pernambuco, Brasil. Coimbra, Memórias Sociedade Broteriana 31: 9112.

Sehnem, A. 1972. Pteridaceae. In: R. Reitz (Ed.). Flora Ilustrada Catarinense. Herbário Barbosa Rodrigues, Itajaí, 244p.

Silva, M. R. da. 2000. Pteridófitas da Mata do Estado - Serra do Mascarenhas, município São Vicente Férrer, estado de Pernambuco, Brasil. Dissertação de Mestrado, Universidade Federal de Pernambuco, Recife.

Strittmatter, C. G. D. 1973. Nueva tecnica de diafanizacion. Boletim de la Sociedad Argentina de Botánica 15(1): 126-129.

Tryon, R. M. \& Stolze, R. G. 1989. Pteridaceae. Pp. 2-81. In: R. M. Tryon \& R. G. Stolze (Eds.) Pteridophyta of Peru. Part. II. 13. Pteridaceae - 15. Dennstaedtiaceae. Fieldiana Botany, Chicago.

Tryon, R. M. \& Tryon, A. F. 1982. Ferns and allied plants with special reference to Tropical America. New York, Springer - Verlag, 857p.

Veloso, H. P. \& Goes Filho, L. 1982. Fitogeografia brasileira, classificação fisionômico - ecológica da vegetação neotropical. Boletim Técnico Projeto RADAMBRASIL. Série Vegetação, Salvador (1): 1-80.

Windisch, P. G. 1983. Pteridófitas da Serra Ricardo Franco (Estado de Mato Grosso) e Aspectos dos seus macrohabitates. Tese de Livre-Docência, Universidade Estadual Paulista "Júlio de Mesquita Filho". Campus de São José do Rio Preto.

Windisch, P. G. 1992. Pteridófitas da Região NorteOcidental do Estado de São Paulo - Guia para excursões. $2^{\mathrm{a}}$ ed. Campus de São José do Rio Preto - SP: UNESP, $110 \mathrm{p}$. 